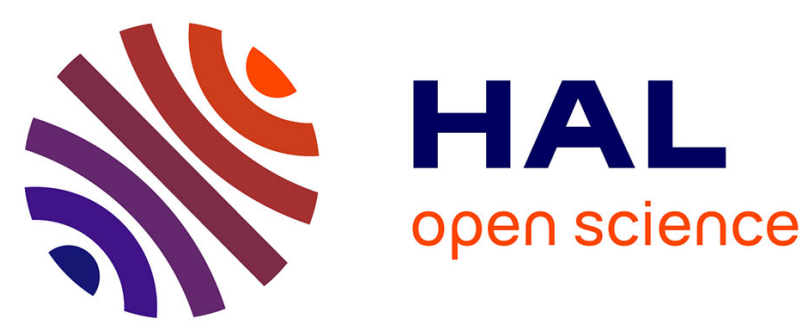

\title{
TEMPERATURE AND MAGNETIC FIELD DEPENDENCE OF MÖSSBAUER SPECTRA OF REDUCED FERREDOXIN FROM CLOSTRIDIUM PASTEURIANUM
}

L. Bogner, F. Parak, K. Gersonde

\section{To cite this version:}

L. Bogner, F. Parak, K. Gersonde. TEMPERATURE AND MAGNETIC FIELD DEPENDENCE OF MÖSSBAUER SPECTRA OF REDUCED FERREDOXIN FROM CLOSTRIDIUM PASTEURIANUM. Journal de Physique Colloques, 1976, 37 (C6), pp.C6-177-C6-180. 10.1051/jphyscol:1976637 . jpa-00216747

\section{HAL Id: jpa-00216747 https://hal.science/jpa-00216747}

Submitted on 1 Jan 1976

HAL is a multi-disciplinary open access archive for the deposit and dissemination of scientific research documents, whether they are published or not. The documents may come from teaching and research institutions in France or abroad, or from public or private research centers.
L'archive ouverte pluridisciplinaire HAL, est destinée au dépôt et à la diffusion de documents scientifiques de niveau recherche, publiés ou non, émanant des établissements d'enseignement et de recherche français ou étrangers, des laboratoires publics ou privés. 


\title{
TEMPERATURE AND MAGNETIC FIELD DEPENDENCE OF MÖSSBAUER SPECTRA OF REDUCED FERREDOXIN FROM CLOSTRIDIUM PASTEURIANUM
}

\author{
L. BOGNER, F. PARAK \\ Physik Department E15 der Technischen Universität München \\ D-8046 Garching, Germany \\ and
}

K. GERSONDE

Abteilung Physiologische Chemie der Rheinisch Westfälischen

Technischen Hochschule Aachen, Germany

\begin{abstract}
Résumé. - Des expériences Mössbauer ont été faites dans un grand domaine de température et de champ magnétique sur du Clostridium Pasteurianum Ferredoxin réduit et sont interprétées en fonction d'un modèle exposé dans un article publié récemment. Les spectres mesurés pour des champs magnétiques intenses et à basses températures ont été calculés par la méthode des moindres carrés en utilisant l'intégrale de transmission.
\end{abstract}

Abstract. - Mössbauer experiments have been performed on reduced Clostridium Pasteurianum Ferredoxin in a wide temperature and magnetic field range and are interpreted in terms of a model, which was developed in an earlier paper. The spectra measured in high magnetic fields and at low temperatures were least squares fitted using the full transmission.

1. Introduction. - Clostridium Pasteurianum Ferredoxin contains in the active center two clusters of iron and sulfur atoms. In each cluster four sulfur and four iron atoms alternatively occupy the corner of a distorted cube. The iron atoms are co-ordinated with cysteine sulfur atoms of the protein moiety.

In an earlier paper [1] a model of the electronic state of the active center of reduced Ferredoxin $\left(\mathrm{Fd}_{\mathrm{red}}\right)$ was developed. Each cluster was described by a wave function $S_{\text {eff }}=\frac{1}{2}$ common to the electrons of all cluster atoms with an effective spin $S_{\text {eff }}=\frac{1}{2}$. The two clusters interact weakly via spin-spin coupling and exchange interaction yielding $S=1$ and $S=0$ states. An external magnetic field breaks the cluster-cluster interaction and each cluster can now be described separately by a wave function corresponding to $S_{\text {eff }}=\frac{1}{2}$.

This model was proved by a least squares fit of Mössbauer spectra, measured at $4.2 \mathrm{~K}$ and $H_{\text {ext }}=0$, $1 \mathrm{~T}, 2 \mathrm{~T}$ respectively and supported by EPR measurements. The theory of the fit used the Hamiltonian,

$$
\begin{aligned}
\mathcal{H}=\beta_{0} \cdot \mathbf{H}_{\mathrm{ext}} \cdot g \cdot \mathbf{S}_{\mathrm{eff}}+ \\
\quad+\beta_{\mathrm{n}} \cdot g_{I} \cdot \sum_{q}(-1)^{q} \mathcal{G}_{q}^{(1)} K_{-q}^{(1)} \\
\quad+P_{z z}\left[3 I_{z}^{2}-I(I+1)\right]-\beta_{\mathrm{n}} \cdot g_{I} \cdot \mathbf{H}_{\mathrm{ext}} \cdot \mathbf{I}
\end{aligned}
$$

where the individual terms are the Zeeman term of the electrons, the magnetic hyperfine interaction, the nuclear quadrupole interaction and the nuclear Zeeman term.

In case of an external magnetic field the fit procedure yields the parameters $\kappa$ and $\rho$, which correspond to the effective magnetic hyperfine fields $H_{\text {eff }}^{\| l}$ and $H_{\text {eff }}^{\perp}$ at one iron nucleus, assuming a $C_{3}$ axis through the iron containing corners of the $\mathrm{Fe}_{4} \mathrm{~S}_{4}$ cube.

The following relations exist :

$$
\begin{aligned}
\left.<1\left|H_{\text {eff }}^{\|}\right| 1\right\rangle & \left.=-<2\left|H_{\text {eff }}^{\| l}\right| 2\right\rangle=-\kappa \cdot \cos \theta \\
\left.<1\left|H_{\text {eff }}^{\perp}\right| 1\right\rangle & =-\left\langle 2\left|H_{\text {eff }}^{\perp}\right| 2\right\rangle \\
& =\frac{1}{\sqrt{2}} \cdot \rho \cdot \sin \theta
\end{aligned}
$$

where $\mid 1>$ and $\mid 2>$ are the two electronic states of the cluster and $\theta$ is the angle between the external field and the threefold symmetry axis of the iron atom. In this paper some new experiments supporting the model described above are presented.

2. Magnetic behaviour of $\mathbf{F} \mathbf{d}_{\text {red }}$ at very low temperatures without external magnetic field. - Mössbauer spectra of 2 cluster $\mathrm{Fd}$ at $4.2 \mathrm{~K}$ without an external magnetic field show essentially one quadrupole 
doublet $[3,8]$. In contrast to this result recent investigations of one cluster $\mathrm{Fd}$ between $4.2 \mathrm{~K}$ and $35 \mathrm{~K}$ show magnetic hyperfine interactions even at $H_{\text {ext }}=0$ [2]. The absence of the magnetic hyperfine pattern in 2 cluster $\mathrm{Fd}$ may be explained in several ways. In the model described in the introduction a cluster-cluster interaction yielding a wave function with $S=1$ or $S=0$ was assumed. In $[3,9,8]$ a spin-spin relaxation mechanism was proposed. In addition there remains still the possibility of a fast spin lattice relaxation, which becomes slow in comparison to the Larmor precession time of the nuclear spin only at very low temperatures. In [8] measurements at $1.3 \mathrm{~K}$ were mentioned yielding the same Mössbauer spectra as those measured at $4.2 \mathrm{~K}$. Figure 1 shows a Mössbauer spectra measured at a temperature of $0.4 \mathrm{~K}$. A $4.2 \mathrm{~K}$ spectrum is given for comparison. The spectra show mainly one quadrupole dublet with essentially the same splitting. The small amount

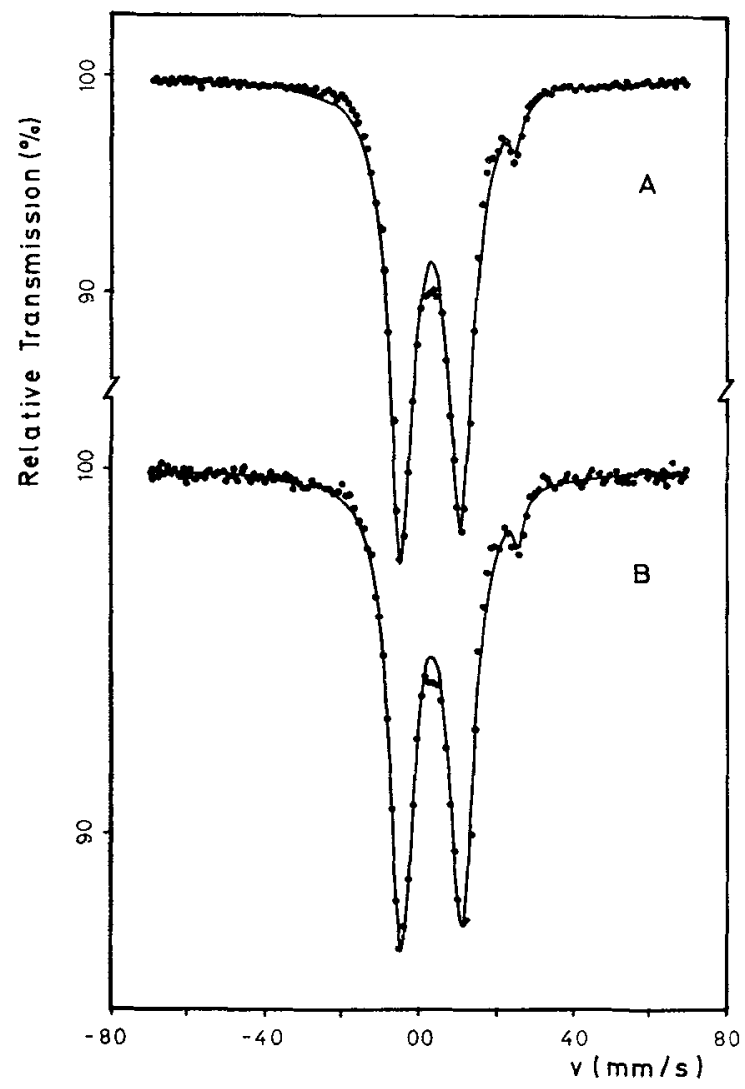

Fig. 1. - Mössbauer spectra of $\mathrm{Fd}_{\text {red }}$ at $\mathbf{H}_{\text {ext }}=0$. The quadrupole splitting $\frac{1}{2} e^{2} q Q$ and the isomer shifts against Rhodium and Palladium respectively are given from:

$A:$ at $4.2 \mathrm{~K}$

$$
\begin{aligned}
& \frac{1}{2} e^{2} q_{1} Q=1.54 \mathrm{~mm} / \mathrm{s}, \quad S_{1}=0.295 \mathrm{~mm} / \mathrm{s}, \\
& \Gamma_{\exp 1}=0.804 \mathrm{~mm} / \mathrm{s}
\end{aligned}
$$

$57 \mathrm{CoRh}$ was used as a source, which was kept at $4.2 \mathrm{~K}$. $B$ : at $0.4 \mathrm{~K}$

$$
\begin{gathered}
\frac{1}{2} e^{2} q_{1} Q=1.521 \mathrm{~mm} / \mathrm{s}, \quad S_{1}=0.347 \mathrm{~mm} / \mathrm{s}, \\
\Gamma_{\exp 1}=0.786 \mathrm{~mm} / \mathrm{s} .
\end{gathered}
$$

${ }^{57} \mathrm{CoPd}$ was used as a source, which was kept at room temperature. of a second dublet with about $5 \%$ of the total intensity of the spectrum with a splitting of about $3.1 \mathrm{~mm} / \mathrm{s} \mathrm{can}$ be attributed to non-cluster iron (high spin $\mathrm{Fe}(\mathrm{II})$, [3]). Since even at $0.4 \mathrm{~K}$ no magnetic hyperfine pattern is found, a pure spin lattice relaxation mechanism becomes highly improbable.

3. Magnetic behaviour at low temperatures and high magnetic fields. - Thel east squares fit of the spectra at $4.2 \mathrm{~K}$ and $H_{\mathrm{ext}}=1 \mathrm{~T}$ and $2 \mathrm{~T}$ mentioned above used the Sum of Lorentzian approach (in the following abbreviated SOL). As pointed out in several publications $[4,5]$ the SOL approximation is no longer valid even at moderate absorber thickness, if the line separations in the spectra are small compared to the line width. As the Ferredoxin absorber is a frozen solution absorber, one has to calculate line positions and intensities for many protein orientations in the external magnetic field ( 8 line pattern for every angle $\theta$ ). This procedure

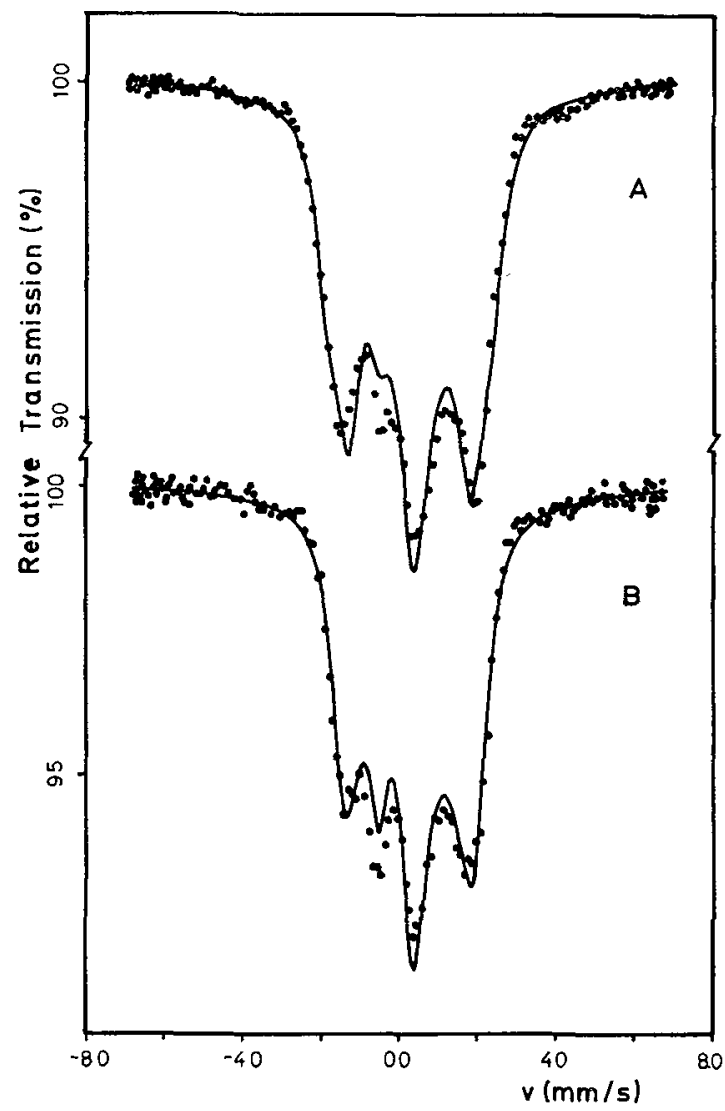

FIG. 2. - Mössbauer spectra of $F \mathrm{~d}_{\text {red }}$ in high magnetic fields : A : $T=4.2 \mathrm{~K}$ and $H_{\text {ext }}=2 T$ (parallel to the $\gamma$-beam)

$$
\begin{gathered}
\kappa=-6.772(2) \mathrm{T}, \quad \rho=12.20(2) \mathrm{T}, \\
\frac{1}{2} e^{2} q Q=1.54 \mathrm{~mm} / \mathrm{s}, \quad S=0.343 \mathrm{~mm} / \mathrm{s}, \quad t_{\mathrm{a}}=1.17 .
\end{gathered}
$$

A $57 \mathrm{CoRh}$ source was used.

B : at $T=0.4 \mathrm{~K}$ and $H_{\text {ext }}=1.41 \mathrm{~T}$ (perpendicular to the $\gamma$-beam) :

$$
\begin{gathered}
\kappa=-6.88(9) \mathrm{T}, \quad \rho=13.1(1) \mathrm{T}, \\
\frac{1}{2} e^{2} q Q=1.54 \mathrm{~mm} / \mathrm{s}, \quad S=0.347 \mathrm{~mm} / \mathrm{s}, \quad t_{\mathrm{a}}=1.19 .
\end{gathered}
$$

A $57 \mathrm{CoPd}$ was used. For the meaning of the parameters compare the text. 
yields more than 70 absorption lines when spectra are calculated for $\Delta \theta=6^{\circ}$. The separation of the lines are small compared to the line width. Therefore the SOL approach may give definitely wrong fitting parameters. In order to see if the SOL method can be used or not, new least squares fits were carried out using the full transmission integral (in the following abbreviated TI) to calculate the shape of the Mössbauer spectrum. The TI for a moved single line source and a split absorber is given by $[6,4]$.

$$
\begin{aligned}
I(v)= & I_{0}\left[1-\mathrm{f}_{\mathrm{s}}+\mathrm{f}_{\mathrm{s}} \cdot \int_{-\infty}^{+\infty} \mathrm{d} E \times\right. \\
& \times \frac{\Gamma_{\mathrm{s}} / 2 \pi}{\left(E-\frac{v}{c} E_{0}\right)^{2}+\left(\Gamma_{\mathrm{s}} / 2\right)^{2}} \\
& \left.\times \exp \left(-\sum_{i=1}^{N} W_{i} \cdot t_{\mathrm{a}} \cdot \frac{\left(\Gamma_{\mathrm{a}} / 2\right)^{2}}{\left(E-E_{i}\right)^{2}+\left(\Gamma_{\mathrm{a}} / 2\right)^{2}}\right)\right] .
\end{aligned}
$$

The numerical integration of this equation has been carried out using standard Gauss-Legendre quadrature technique [7] in a similar way as described in [5].

Figure 2 shows spectra at $0.4 \mathrm{~K}$ with $\mathrm{H}_{\text {ext }}=1.41 \mathrm{~T}$ perpendicular to the $\gamma$-beam and at $4.2 \mathrm{~K}$ with $H_{\text {ext }}=2 \mathrm{~T}$ parallel to the $\gamma$-beam. The least squares fit procedure used the TI theory. The fit yields values for the hyperfine parameters $\kappa$ and $\rho$ (the quadrupole splitting was fixed at $1.52 \mathrm{~mm} / \mathrm{s}$ and $1.54 \mathrm{~mm} / \mathrm{s}$ respectively), which are very similar to those obtained by a SOL fit. The values are given in table I.

\section{TABLE I}

Magnetic hyperfine parameters $\kappa$ and $\rho$ of $\mathrm{Fd}_{\text {red }}$ at high magnetic fields and low temperatures. The results were obtained using the Sum-of-Lorentzian approximation and the full transmission integral respectively. are :

The parameters at $T=0.4 \mathrm{~K}$ and $H_{\text {ext }}=1.41 \mathrm{~T}$

$$
\begin{array}{ll}
\kappa_{\mathrm{TI}}=-6.88(9) \mathrm{T}, & \kappa_{\mathrm{SOL}}=-6.5(2) \mathrm{T} \\
\rho_{\mathrm{TI}}=13.1(1) \mathrm{T}, & \rho_{\mathrm{SOL}}=13.4(2) \mathrm{T} .
\end{array}
$$

The parameters at $T=4.2 \mathrm{~K}$ and $H_{\mathrm{ext}}=2 \mathrm{~T}$ are :

$$
\begin{array}{ll}
\kappa_{\mathrm{TI}}=-6.772(2) \mathrm{T}, & \kappa_{\mathrm{SOL}}=-6.91(1) \mathrm{T} \\
\rho_{\mathrm{TI}}=12.20(2) \mathrm{T}, & \rho_{\mathrm{SOL}}=12.76(2) \mathrm{T} .
\end{array}
$$

This result shows that the errors made in the fit parameter determination using the SOL approach can average to zero if the number of hyperfine lines is very high. To prove this behaviour we calculated Mössbauer spectra at $H_{\text {ext }}=2 \mathrm{~T}$ with the TI and fitted to them theoretical functions using SOL approach, thus receiving values for the deviation of the hyperfine parameters. This procedure was carried out for several spectra with varying number of hyperfine lines.
To get different numbers of lines the number of protein orientations in the external field (angle $\theta$ ) in the calculation of the Mössbauer spectrum of the frozen solution absorber was varied. Figure 3 shows the differences between TI and SOL fit procedures. At relatively small numbers of hyperfine lines the parameter deviation is higher

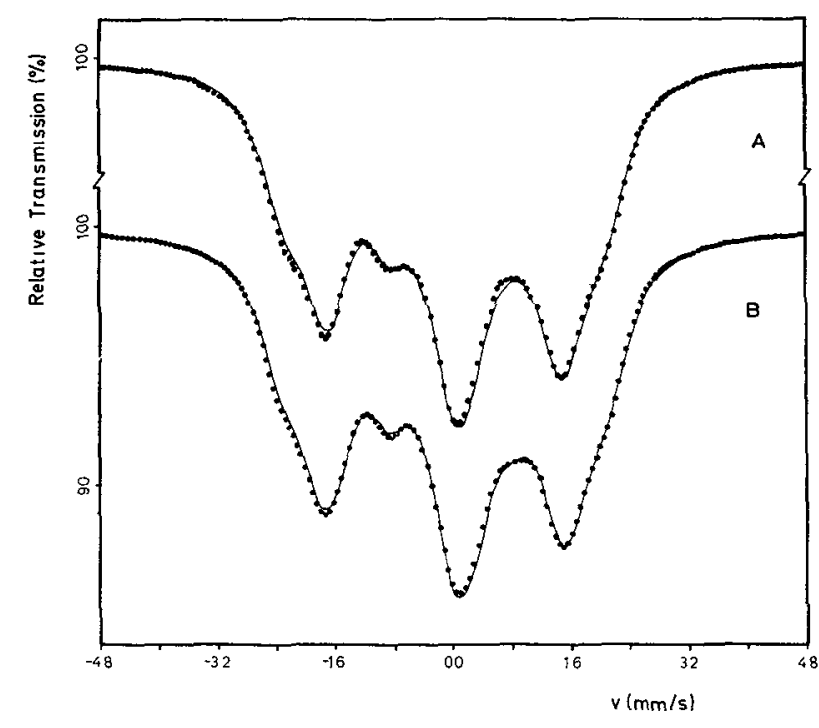

FIG. 3. - Calculated transmission integral Mössbauer spectra fitted with Sum-of-Lorentzian theory. $H_{\text {ext }}=2 \mathrm{~T}$ applied parallel to the $\gamma$-beam.

$$
\begin{aligned}
(\kappa)_{\mathrm{TI}} & =-6.87 \mathrm{~T}, & (\rho)_{\mathrm{TI}} & =13.10 \mathrm{~T}, \\
\frac{1}{2} e^{2} q Q & =1.54 \mathrm{~mm} / \mathrm{s}, & t_{\mathrm{a}} & =1.118 .
\end{aligned}
$$

A : 70 lines (31 angular steps),

$$
\frac{\Delta \kappa(\mathrm{SOL})}{\kappa(\mathrm{TI})}=1.5 \%, \quad \frac{\Delta \rho(\mathrm{SOL})}{\rho(\mathrm{TI})}=0.1 \% .
$$

B : 34 lines (4 angular steps),

$$
\frac{\Delta \kappa(\mathrm{SOL})}{\kappa(\mathrm{TI})}=2.8 \%, \quad \frac{\Delta \rho(\mathrm{SOL})}{\rho(\mathrm{TI})}=0.4 \% .
$$

$\left[\frac{\Delta \kappa(\mathrm{SOL})}{\kappa(\mathrm{TI})}=2.8 \%, \frac{\Delta \rho(\mathrm{SOL})}{\rho(\mathrm{TI})}=0.4 \%\right.$,

fitted with $\Delta \theta=45^{\circ}$ which corresponds to 34 lines] than in the spectra with a great number of lines

$$
\left[\frac{\Delta \kappa(\mathrm{SOL})}{\kappa(\mathrm{TI})}=1.5 \%, \frac{\Delta \rho(\mathrm{SOL})}{\rho(\mathrm{TI})}=0.1 \%,\right.
$$

fitted with $\Delta \theta=6^{\circ}$ which corresponds to 70 lines].

Our result shows, that Mössbauer spectra of $F d_{\text {red }}$ in high magnetic fields can be reasonably well fitted using the Hamiltonian described above and the SOL approach. The parameters $\kappa$ and $\rho$ are essentially equal at $0.4 \mathrm{~K}$ and $4.2 \mathrm{~K}$ and the different magnetic fields in agreement with our model. The spectrum at $0.4 \mathrm{~K}$ and $1.41 \mathrm{~T}$ can only be fitted with a positive electric field gradient. 
4. Magnetic behaviour at higher temperatures in high magnetic fields. - When rising the temperature above $15 \mathrm{~K}$, the Mössbauer spectra of $\mathrm{Fd}_{\text {red }}$ at high magnetic fields changes drastically. Above $20 \mathrm{~K}$ x-band EPR spectra of $\mathrm{Fd}_{\mathrm{red}}$ show no signal. For this behaviour fast spin-lattice relaxation effects may be responsible. In such a case it is necessary to average over the contributions of the different electronic levels to the magnetic hyperfine field. When the relaxation time is short as compared to the nuclear Larmor precession time the second term in the Hamiltonian averages to zero. Using this modified Hamiltonian we could fit spectra at $\mathrm{H}_{\mathrm{e} x \mathrm{t}}=2.8 \mathrm{~T}$ in the temperature region between $40 \mathrm{~K}$ and $120 \mathrm{~K}$ reasonably well. Spectra, measured in the region between $15 \mathrm{~K}$ and $40 \mathrm{~K}$ at $H_{\text {ext }}=2.8 \mathrm{~T}$ clearly show magnetic splitting with relaxation effects (Fig. 4). At this magnetic field the coupling of the clusters should be broken and spin lattice relaxation of the isolated cluster spin $\left(S_{\text {eff }}=1 / 2\right)$ should be responsible for the shape of the spectra. It should be mentioned that those fits were again performed with $q>0$.

FIG. 4. - Mössbauer spectra of Fdred at $H_{\text {ext }}=2.8 \mathrm{~T}$ applied parallel to the $\gamma$-beam :

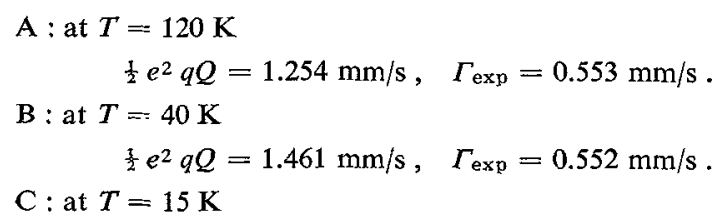

Acknowledgements. - The authors wish to thank Prof. G. M. Kalvius for this continuous support of this work.

This work was supported by the Deutsche Forschungsgemeinschaft.

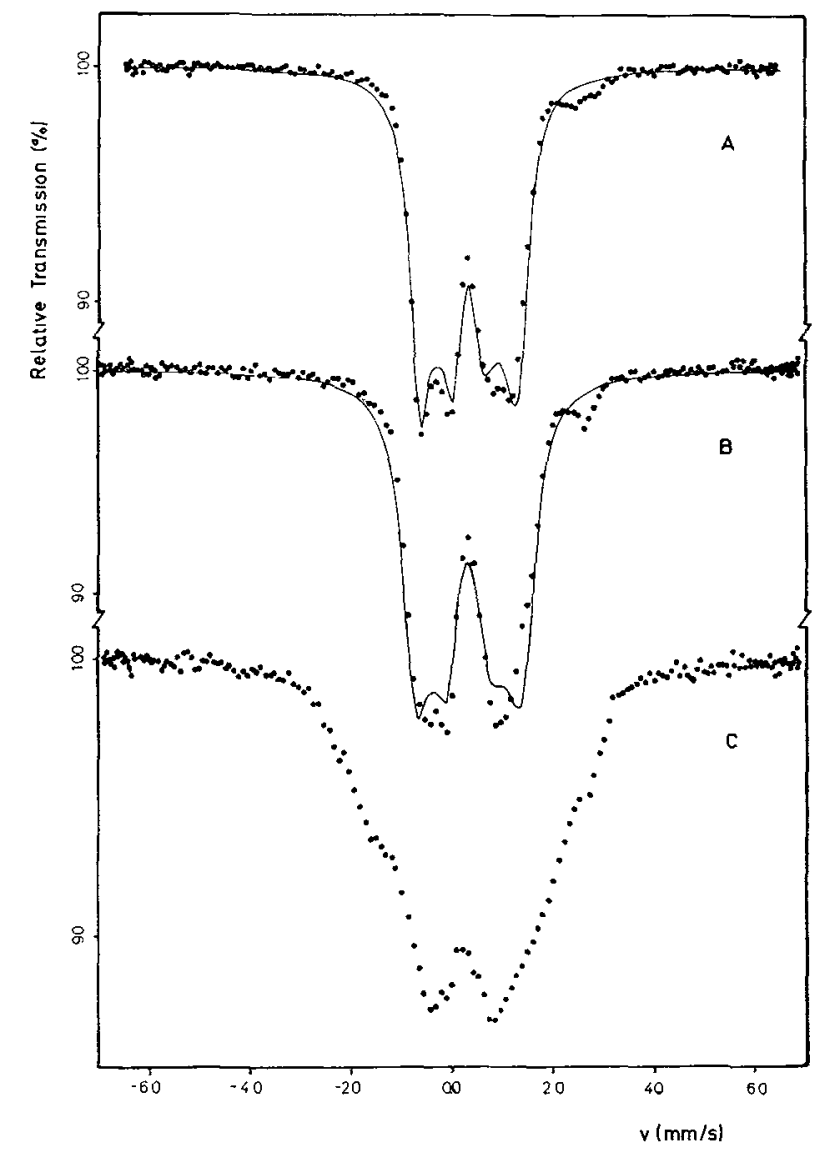

\section{References}

[1] Eicher, H., Parak, F., Bogner, L., Gersonde, K., Z. Naturforsch. 29C (1974) 683.

[2] Mullinger, R. N., Cammack, R., Rao, K. K., Hall, D. O., Drckson, D. P., Johnson, C. E., Rush, J., SimopouLos, A., Biochem. J. 151 (1975) 75.

[3] Gersonde, K., Schlaak, H. E., Breitenbach, M., Parak, F., Ercher, H., Zgorzalla, W., Kalvius, M. G., Mayer, A. Europ. J. Bioch. 43 (1974) 307.

[4] Gerdau, E., Räth, W., Winkler, H., Z. Phys. 257 (1972) 29.

[5] Shenoy, G. K., Friedt, J. M., Maletta, H., Ruby, S. L., in Mössbauer Effekt Methodology, Vol. 9, ed. I. J. Gruverman, C. W. Seidel.

[6] Margulies, S., Ehrman, J. R., Nucl. Instr. Meth. 12 (1961) 131.

[7] STOER, J., Einführung in die numerische Mathematik I (Springer Verlag Berlin, Heidelberg) 1972, p. 118.

[8] Thompson, C. L., Johnson, C. E., Dickson, D. P. E., Cammack, R., Hall, D. O., Weser, U., Rao K. K., Biochem. J. 139 (1974) 97.

[9] Mathews, R., Charlton, S., Sands, R. H., Palmer, G., J. Biol. Chem. 249 (1974) 4326. 